\title{
ECOLOGY OF THE GREATER YELLOWSTONE ECOSYSTEM
}

\section{INSTRUCTOR $\uparrow$ SCOTT CARLTON $\uparrow$ LARAMIE COUNTY COMMUNITY COLLEGE $\uparrow$ LARAMIE}

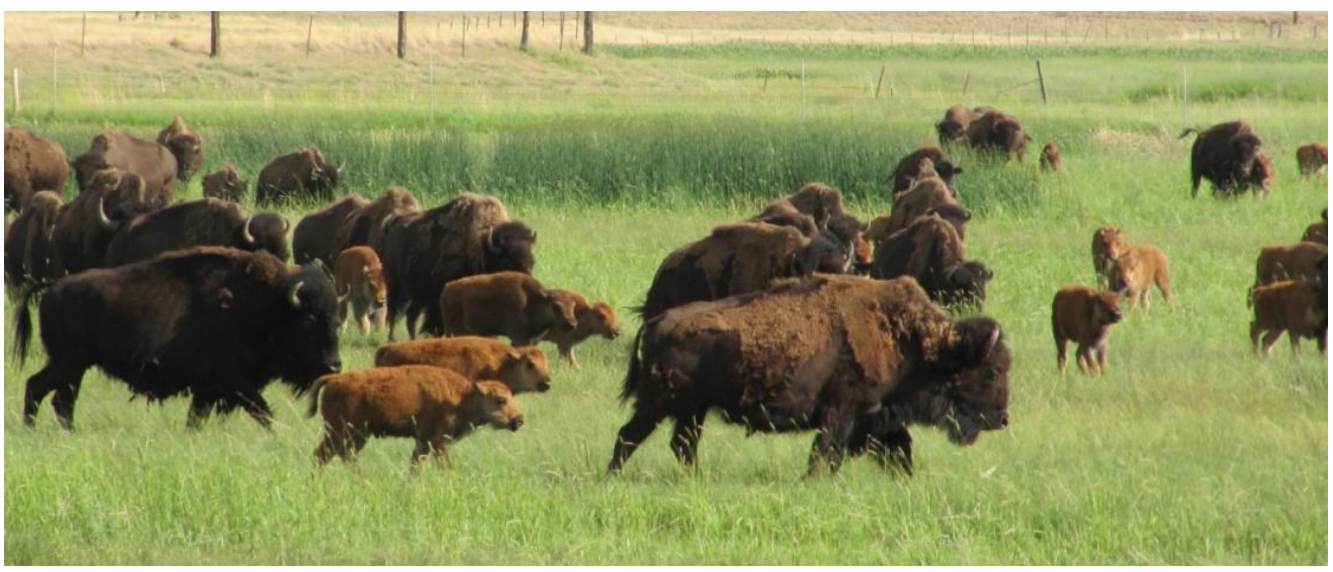

Figure 1. Issues investigated included ungulate grazing (photo by C. Havener).

\section{$\uparrow \quad$ Class OVERVIEW}

During June, 2010 six wildlife students from Laramie, WY traveled to Grand Teton and Yellowstone National Parks for a 10 day course on the Ecology of the Greater Yellowstone Ecosystem. The course focused on the vegetation, animals, geology, and management challenges concerning the parks. For each of the components, a student gave a brief introduction to the class on the topic we would be exploring that day. Students learned to identify trees using dichotomous keys and then spent the day in the field performing vegetation transects in recently burned to mature forests within the parks. Students then used their data sets to make inferences into species composition and the process of succession across the landscape. Students learned about individual tree life histories. including the role of serotiny in early forest successional stages following a fire.

The geology of Yellowstone National Park was explored by visiting and talking about the volcanic history of the park, the various geysers and hot springs, and the biota that inhabit these springs. This was an excellent opportunity to introduce the students to survival in extreme environments. Students were able to spend the morning with bison biologists for the park where they had the opportunity to hear about the challenges both ecological and political in managing bison herds. Students then spent the remainder of the day tracking bison using VHF telemetry and performing behavioral observations on large herds.

The fisheries crew in charge of lake trout removal hosted the students for a day on Yellowstone Lake. Students participated in assisting fisheries biologists in pulling nets and removing lake trout captured in the nets. They were able to interact with park biologists and see firsthand one of the challenges with maintaining native fish species by trying to control non-native fish species.

This course exposed wildlife students to many facets of Grand Teton and Yellowstone National Parks and allowed them to interact one on one with park biologists. 